\title{
The diaphragm has an expiratory braking effect in spontaneously breathing lung injured animals as shown by electrical diaphragmatic activity
}

\author{
M Pellegrini ${ }^{1,2 *}$, G Hedenstierna ${ }^{3}$, A Roneus ${ }^{1}$, M Segelsjö ${ }^{4}$, A Larsson', G Perchiazzi ${ }^{1,2}$ \\ From ESICM LIVES 2015 \\ Berlin, Germany. 3-7 October 2015
}

\begin{abstract}
Introduction
Albeit defined as an inspiratory muscle, the diaphragm interacts with the respiratory system also during expiration. The expiratory load on the diaphragm derives from lung volume and hence, possibly from lung collapse. We hypothesized that the diaphragm has a braking effect during the whole expiration, preserving lung patency during SB in collapse prone lungs. We investigated this hypothesis by measuring the expiratory electrical diaphragmatic activity (EAdi $\mathrm{exp}_{\text {p }}$ ) in the modulation of expiratory flow (V'exp) in a porcine model.
\end{abstract}

\section{Methods}

Mild acute respiratory distress syndrome (ARDS) was induced in 7 anesthetized, tracheostomized pigs by repeated lung lavages, targeting a $\mathrm{PaO}_{2} / \mathrm{FiO}_{2}$ of 250 $\mathrm{mmHg}$. After stabilization, the animals were converted to spontaneous breathing (SB) and underwent a decremental continuous positive airway pressure (CPAP) trial of 15, 12, 9, 6, 3 and $0 \mathrm{cmH}_{2} \mathrm{O}$, while EAdi $\mathrm{exp}_{\text {exp }}$ and the expiratory trans-diaphragmatic pressure ( $\mathrm{Pdi}_{\mathrm{exp}}$ ) were measured. In two of the pigs EAdi $\mathrm{exp}_{\text {exp }}$ and $\mathrm{Pdi}_{\exp }$ were assessed also during controlled mechanical ventilation (CMV) after muscle relaxation using the same positive end-expiratory pressure (PEEP) as for CPAP. For each studied condition, lung volume was assessed by profiting of sulfur hexafluoride $\left(\mathrm{SF}_{6}\right)$ washin/washout technique. The V'exp slope before the expiratory peak flow and the expiratory volume $\left(\mathrm{Vol}_{\text {exp }}\right)$ at $50 \%$ and $75 \%$ of expiratory time were estimated. Statistical significance of expiratory EAdi $\mathrm{exp}_{\mathrm{exp}} / \mathrm{Pdi}_{\exp }$ was assessed by F-tests $(\alpha=0.05)$. Between SB and CMV, comparisons were performed at the same lung volume,

${ }^{1}$ Hedenstierna Laboratory - Uppsala University, Department of Surgical

Sciences, Uppsala, Sweden

Full list of author information is available at the end of the article which was verified by applying the Kolmogorov-Smirnov test $(\alpha=0.05)$.

\section{Results}

When CPAP was decreased, EAdi $\mathrm{exp}_{\text {exp }}$ increased until a CPAP of $6 \mathrm{cmH}_{2} \mathrm{O}$ and then remained unaltered (although elevated) with further decrease in CPAP. EAdi $i_{\text {exp }}$ and $\mathrm{Pdi}_{\exp }$ were tightly correlated as confirmed by an $\mathrm{R}^{2}>0.82$ $(\mathrm{p}<0.01)$. Lung volumes were comparable during SB and CMV when exposed to the same CPAP/PEEP levels. V'exp had a slower initial increase (before reaching its peak) during SB than during CMV. By decreasing CPAP/PEEP, V'exp rise was markedly more delayed during $\mathrm{SB}$ than during CMV at the same lung volumes indicating a delayed emptying of the lungs, which was also shown by that $\mathrm{Vol}_{\text {exp }}$ at $50 \%$ and at $75 \%$ of expiration were higher during $\mathrm{SB}$ than during $\mathrm{CMV}$.

\section{Conclusions}

The findings suggest that the diaphragm plays an important role during expiration. The EAdi exp $_{\text {p }}$ modulates diaphragmatic expiratory mechanical "braking" activity, possibly to protect against reductions in lung volume and atelectasis formation. The EAdi ${ }_{\exp }$ can be useful in setting CPAP/PEEP during SB in mild ARDS conditions.

\section{Grant Acknowledgment}

The School of Anesthesia and Intensive Care of Medicine, Bari University, Italy; The Swedish Heart and Lung Foundation.

\section{Authors' details}

'Hedenstierna Laboratory - Uppsala University, Department of Surgical Sciences, Uppsala, Sweden. ${ }^{2}$ Bari University, Department of Emergency and Organ Transplant, Bari, Italy. ${ }^{3}$ Hedenstierna Laboratory - Uppsala University, 
Department of Medical Sciences, Uppsala, Sweden. ${ }^{4}$ Section of Radiology Uppsala University, Department of Surgical Sciences, Uppsala, Sweden.

Published: 1 October 2015

doi:10.1186/2197-425X-3-S1-A572

Cite this article as: Pellegrini et al:: The diaphragm has an expiratory braking effect in spontaneously breathing lung injured animals as shown by electrical diaphragmatic activity. Intensive Care Medicine Experimental 2015 3(Suppl 1):A572.

\section{Submit your manuscript to a SpringerOpen ${ }^{\circ}$ journal and benefit from:}

- Convenient online submission

- Rigorous peer review

- Immediate publication on acceptance

- Open access: articles freely available online

- High visibility within the field

- Retaining the copyright to your article

Submit your next manuscript at $\gg$ springeropen.com 